\title{
Natural Product-Based Phenols as Novel Probes for Mycobacterial and Fungal Carbonic Anhydrases
}

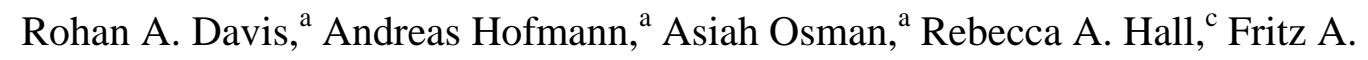
Mühlschlegel, ${ }^{\mathrm{c}, \mathrm{d}}$ Daniela Vullo, ${ }^{\mathrm{b}}$ Alessio Innocenti, ${ }^{\mathrm{b}}$ Claudiu T. Supuran, ${ }^{\mathrm{b},{ }^{*}}$ and Sally-Ann

$$
\text { Poulsen }^{\mathrm{a}, *}
$$

${ }^{a}$ Eskitis Institute, Griffith University, Nathan, Queensland 4111, Australia.

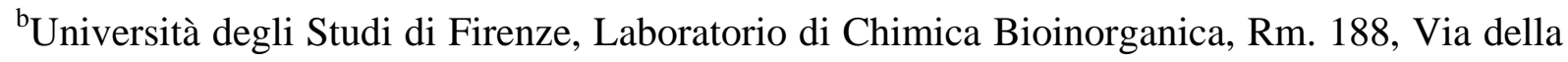
Lastruccia 3, 50019 Sesto Fiorentino, Florence, Italy.

${ }^{\mathrm{c}}$ School of Biosciences, University of Kent, Canterbury, Kent CT2 7NJ, United Kingdom.

${ }^{\mathrm{d}}$ East Kent Hospitals University NHS Foundation Trust, Clinical Microbiology Service, Ashford, Kent, TN24 0LZ, United Kingdom.

\section{${ }^{*}$ Corresponding authors}

Tel: +61-7-37357825; Fax: +61-7-37356001; E-mail: s.poulsen@griffith.edu.au (S-AP).

Tel: +39-055-4573005; Fax: +39-055-4573385; E-mail: claudiu.supuran@unifi.it (CTS)

$¥$ Nonstandard abbreviations: CA, carbonic anhydrase; NP, natural product; TB, tuberculosis; AIDS, acquired immune deficiency syndrome; SAR, structure-activity relationship; SA, sulfanilamide; AZA, acetazolamide; ZNS, zonisamide; TPM, topiramate; PDB, protein data bank.

${ }^{\dagger}$ Coordinates and structure factors have been deposited with the PDB (accession codes: 3NB5 (CA II:18) and 3P4V (CA II:6b). 


\begin{abstract}
In order to discover novel probes that may help in the investigation and control of infectious diseases through a new mechanism of action, we have evaluated a library of phenol-based natural products (NPs) for enzyme inhibition against four recently characterized pathogen $\beta$ family carbonic anhydrases (CAs). These include CAs from Mycobacterium tuberculosis, Candida albicans and Cryptococcus neoformans as well as $\alpha$-family human CA I and II, for comparison. Many of the NPs selectively inhibited the mycobacterial and fungal $\beta$-CAs, with the two best performing compounds displaying submicromolar inhibition with a preference of fungal over human CA inhibition of more than two orders of magnitude. These compounds provide the first example of non-sulfonamide inhibitors that display $\beta$ over $\alpha$ CA enzyme selectivity. Structural characterisation of the library compounds in complex with human CA II revealed a novel binding mode whereby a methyl ester interacts via a water molecule with the active site zinc.
\end{abstract}




\section{Introduction}

The widespread use and over-use of antimicrobial drugs over the past 30 years has given rise to emerging resistance and poses a severe limitation to the application of antibiotics with bacterial pathogens. ${ }^{1}$ Multi-drug resistant and extensively multi-drug resistant tuberculosis (TB) is now present in many countries. Mycobacterium tuberculosis, the microbe responsible for TB, has developed a reduced susceptibility to clinically used drugs, all of which were introduced 30-40 years ago. ${ }^{2,3}$ A similar situation is arising with fungal pathogens, such as Candida albicans and Cryptococcus neoformans, which can cause debilitating oral and genital infections, but also lead to systemic infections with high mortality, especially in immuno-compromised patients including patients suffering from AIDS or undergoing chemotherapy or organ transplantation. ${ }^{4-6}$

Anti-infective drug resistance presents a serious and immediate medical threat that requires urgent development of new drugs that ideally possess a novel mechanism of action. CAs (EC 4.2.1.1) are zinc metalloenzymes that catalyze the reversible hydration of carbon dioxide to give bicarbonate and a proton: $\mathrm{CO}_{2}+\mathrm{H}_{2} \mathrm{O} \leftrightarrows \mathrm{HCO}_{3}^{-}+\mathrm{H}^{+}$. CAs constitute an excellent example of convergent evolution, ${ }^{8}$ and in addition to $\alpha$-CAs from mammals there are four distinct, unrelated gene families $(\beta-, \gamma-, \delta$ - and $\zeta$-CA families) that encode these metalloenzymes in organisms across the phylogenetic tree. ${ }^{7,8}$ Mammals possess only $\alpha$-CAs, whilst many pathogenic organisms, such as bacteria and fungi encode $\beta$-CAs. Similarly to $\alpha$ CAs, a zinc cation defines the location of the active site of the $\beta$-CA enzymes. The $\beta$-CAs from Helicobacter pylori, Candida albicans, Candida glabrata, Cryptococcus neoformans and Brucella suis are essential for growth and have proven susceptible to inhibition with several compound classes including sulfonamides, carboxylates and boronic acids. ${ }^{9-16} \mathrm{~A}$ positive correlation from enzyme assays to a cell-based anti-infective phenotype demonstrates that the $\beta$-CAs from these pathogens are potential druggable targets for anti-infective therapies.

We recently reported a novel class of CA inhibitors belonging to the coumarin chemotype. ${ }^{17}$ In that study the NP coumarin, 6-(1S-hydroxy-3-methylbutyl)-7-methoxy-2H-chromen-2-one, displayed significant CA inhibitory properties and was later shown using protein $\mathrm{X}$-ray crystallography to be hydrolyzed within the CA active site with formation of the cis-2hydroxy-cinnamic acid derivative $\mathbf{C I N},{ }^{17}$ Figure 1 . This coumarin suicide inhibitor exhibited 
a completely unprecedented binding mode, with no interactions between the inhibitor molecule and the active site $\mathrm{Zn}^{2+}$ observed. ${ }^{17}$ In another contribution, Parkkila and colleagues $^{18}$ showed that imatinib and nilotinib (clinically used protein tyrosine kinase inhibitors with potent antitumor activity) were low nanomolar inhibitors of $\alpha$-CA I and II, Figure 1. The striking feature of these inhibitors is they lack the zinc binding sulfonamide group of classical CA inhibitors. There is precedence for a non-classical ligand binding mode to mammalian CAs as reported by Christianson and colleagues. ${ }^{19}$ The crystal structure of human CA II in complex with the inhibitor phenol revealed this inhibitor bound in the active site cleft mainly because of van der Waals contacts with side chain residues of the hydrophobic side of the active site. The hydroxyl group of the inhibitor was found to interact with a zinc-bound water molecule through hydrogen bonding. Intriguingly, there was no direct interaction between the inhibitor and the zinc ion.

Figure 1. Recently discovered CA inhibitors with a novel CA enzyme binding chemotype.
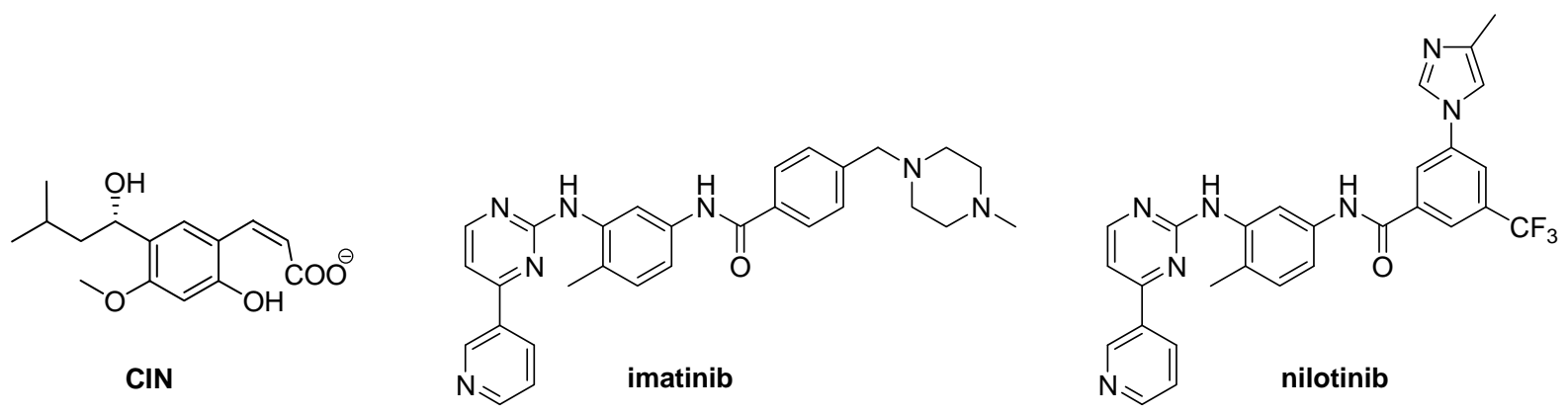

Based on these observations it appears that new chemotypes possess the potential to provide novel CA inhibitors with drug-like properties. In this study, we thus employed a library of NP-based phenols to elucidate the structure-activity relationship of the phenol skeleton for inhibition of CAs from pathogenic organisms as well as human CA I and II. The pathogen

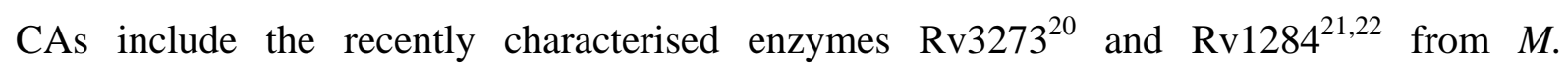
tuberculosis, and from C. albicans (Nce103) ${ }^{23}$ and C. neoformans (Can2). ${ }^{24}$ Rv1284 is generally believed to be essential for survival of the mycobacterium, and was found to be highly up-regulated under starvation conditions. ${ }^{25}$ In contrast, there is no evidence suggesting that Rv3273 is essential for mycobacterial growth. ${ }^{25,26}$ In yeast, a growth-defect phenotype has been observed upon deletion of NCE103 which only occurs under aerobic conditions. ${ }^{27}$ Can2 is a crucial component of the $\mathrm{CO}_{2}$ sensing system of $C$. neoformans. In response to 
elevated $\mathrm{CO}_{2}$ levels, this fungus produces a polysaccharide capsule which has been identified as a major virulence factor for this pathogen. ${ }^{28}$ This current study provides further grounding for the discovery of much needed novel small molecule probes to investigate the possible management of these infections through a new mechanism of action.

\section{Results and Discussion}

\subsection{Compound library}

As part of the ongoing collaborative research effort towards the discovery of novel NP inhibitors of CAs ${ }^{17,29}$ a library of phenolic NPs (1-13, Figure 2) and synthetic phenols based on a NP scaffold (14-21, Figure 3) was assembled and considered for M. tuberculosis, C. albicans and C. neoformans $\beta$-CA and human CA I and II inhibitory investigations. Although diverse in structure, the library compounds share a common structural feature comprising at least one phenolic fragment. Compounds were chosen from a unique NP-based library. Phenols that were isolated or synthesised in quantities greater than 1 milligram were used in the current studies. The majority of these $\mathbf{2 3}$ compounds used in this work are from a variety of structure classes that cannot be readily accessed by other means. The NP library consisted of eight fungal (1-6a, 9-10), two ascidian $(\mathbf{7}, \mathbf{8})$ and three plant (11-13) secondary metabolites. Specifically, the NPs were a series of simple mono- or disubstituted phenols $1-5,{ }^{30-32}(-)-$ xylariamide A $\mathbf{6 a}{ }^{33}$ and its synthetic enantiomer (+)-xylariamide A $\mathbf{6 b},{ }^{33}$ polyandrocarpamine A 7, polyandrocarpamine B 8, ${ }^{34,35}$ xanthones 9 and $10,{ }^{36}$ endiandrin A $\mathbf{1 1},{ }^{37}$ endiandrin B $\mathbf{1 2},{ }^{38}$ and (-)-dihydroguaiaretic acid $13 .^{37,38}$ The synthetic phenolic library 14-21 consisted of eight secondary amides that each elaborates the NP scaffold present in the fungal metabolite 5. ${ }^{30,39}$ The compounds have been assessed for human mitochondrial CA inhibition, with inhibition constants in the range of $0.070-0.125 \mu \mathrm{M} .{ }^{29}$ None of the compounds have been screened for CA inhibitory effects against the pathogen $\beta$-CA family until now. Specifically, we have investigated this NP-based library against $\beta$-CAs from the bacterial pathogen $M$. tuberculosis encoded by the genes Rv3273 and Rv1284, the fungal pathogens C. albicans and C. neoformans encoded by the genes Nce103 and Can2, respectively as well as the physiologically dominant human isoforms $\alpha$-CA I (low activity) and II (high activity). For comparison, we also included the clinically used CA inhibitors sulfanilamide SA, acetazolamide AZA, zonisamide ZNS and the sulfamate, topiramate TPM (Figure 4), as well as phenol. 
Figure 2. Phenol and the NPs 1-13 containing a phenolic fragment.<smiles>Oc1ccccc1</smiles>

phenol<smiles>OCCc1ccc(O)cc1</smiles>

1<smiles>[R]C(=O)Cc1ccc(O)c([R1])c1</smiles>

$2 \mathrm{R}_{1}=\mathrm{H} \quad \mathrm{R}_{2}=\mathrm{OH}$

$3 \mathrm{R}_{1}=\mathrm{H} \quad \mathrm{R}_{2}=\mathrm{NH}_{2}$

$4 \mathrm{R}_{1}=\mathrm{Cl} \mathrm{R}=\mathrm{OH}$

$5 \mathrm{R}_{1}=\mathrm{Cl} \mathrm{R}=\mathrm{NH}_{2}$<smiles>COC(=O)/C=C/C(=O)N[C@@H](Cc1ccc(O)c(Cl)c1)C(=O)O</smiles>

$6 a$<smiles>COC(=O)/C=C/C(=O)N[C@@H](Cc1ccc(O)c(Cl)c1)C(=O)O</smiles>

$6 b$<smiles>[R4]Oc1cc(/C=C2\N=C(N)NC2=O)ccc1O</smiles>

$7 \mathrm{R}_{1}=\mathrm{CH}_{3}$ $8 \mathrm{R}_{1}=\mathrm{H}$<smiles>[R14]/C=C\CO</smiles><smiles>COc1cc([C@H]2[C@H](C)[C@@H](C)[C@H]2c2ccc(O)c(OC)c2)ccc1O</smiles><smiles>COc1cc([C@H]2[C@@H](C)[C@@H](C)[C@H]2c2ccc(O)c(OC)c2)ccc1O</smiles>

11<smiles>COc1cc(C[C@H](C)[C@H](C)Cc2ccc(O)c(OC)c2)ccc1O</smiles>
13 
Figure 3. Synthetic NP-based phenols (14-21).<smiles>O=C(Cc1ccc(O)c(Cl)c1)NCc1ccccc1</smiles>

14<smiles>COc1cccc(CCNC(=O)Cc2ccc(O)c(Cl)c2)c1</smiles>

16<smiles>NS(=O)(=O)c1ccc(CCNC(=O)Cc2ccc(O)c(Cl)c2)cc1</smiles><smiles>CC(C)(C)NC(=O)Cc1ccc(O)c(Cl)c1</smiles><smiles>O=C(Cc1ccc(O)c(Cl)c1)NCCc1ccccc1</smiles>

15<smiles>COc1ccc(CCNC(=O)Cc2ccc(O)c(Cl)c2)cc1OC</smiles><smiles>COCCNC(=O)Cc1ccc(O)c(Cl)c1</smiles><smiles>CCCCNC(=O)Cc1ccc(O)c(Cl)c1</smiles> 
Figure 4. Clinically used CA inhibitors with a sulfonamide or sulfamate zinc binding group.<smiles>Nc1ccc(S(N)(=O)=O)cc1</smiles>

SA<smiles>CC(=O)Nc1nnc(S(N)(=O)=O)s1</smiles>

AZA<smiles>NS(=O)(=O)Cc1noc2ccccc12</smiles>

ZNS<smiles>CC1(C)O[C@H]2CO[C@]3(COS(N)(=O)=O)OC(C)(C)O[C@H]3[C@H]2O1</smiles>

\subsection{Carbonic Anhydrase Inhibition}

The inhibitory activity of the compounds shown in Figures 2-4 against human CA I and II as host off-target enzymes, as well as the $M$. tuberculosis $\beta$-CAs encoded by genes Rv3273 and Rv1284, C. albicans $\beta$-CA encoded by the gene Nce103 and the $C$. neoformans $\beta$-CA encoded by the gene Can2 are presented in Table 1. This inhibition data was acquired using a stopped flow assay that monitors the physiological reaction, that is, the CA catalyzed hydration of $\mathrm{CO}_{2}{ }^{40}$ 
Table 1: Enzyme inhibition of pathogenic M. tuberculosis $\beta$-CA isozymes Rv3273 and Rv1284, C. albicans isozyme Nce103 and C. neoformans isozyme Can2 and human $\alpha$-CA isozymes I and II, with the NP-based library (1-21), known CA inhibitors (SA, AZA, ZNS and TPM) and phenol.

\begin{tabular}{|c|c|c|c|c|c|c|}
\hline \multirow[t]{2}{*}{ Compound } & \multicolumn{6}{|c|}{$\mathrm{K}_{\mathrm{i}}(\mu \mathrm{M})^{a, b}$} \\
\hline & Rv3273 & Rv1284 & Nce103 & Can2 & CA I & CA II \\
\hline 1 & 12.1 & 0.85 & 1.10 & 1.08 & 430 & 8.7 \\
\hline 2 & 11.4 & 10.8 & 1.02 & 0.90 & 309 & 10.3 \\
\hline 3 & 9.12 & 0.85 & 0.91 & 0.84 & 309 & 11.2 \\
\hline 4 & 10.8 & 10.3 & 1.08 & 1.12 & 265 & 8.6 \\
\hline 5 & 11.2 & 10.5 & 1.00 & 0.85 & 237 & 131 \\
\hline $6 a$ & 11.3 & 0.84 & 1.03 & 1.15 & 239 & 8.3 \\
\hline $6 b$ & 10.9 & 0.71 & 1.06 & 1.11 & 231 & 8.0 \\
\hline 7 & 0.91 & 11.8 & 0.92 & 0.89 & 10.5 & 9.6 \\
\hline 8 & 0.92 & 0.91 & 0.90 & 0.95 & 355 & 13.1 \\
\hline 9 & 11.4 & 10.5 & 1.06 & 1.12 & 201 & 8.4 \\
\hline 10 & 10.9 & 0.99 & 1.01 & 1.08 & 374 & 9.2 \\
\hline 11 & 8.92 & 0.82 & 0.73 & 0.77 & 368 & 11.7 \\
\hline 12 & 0.89 & 0.80 & 0.70 & 0.95 & 354 & 12.1 \\
\hline 13 & 9.10 & 0.85 & 0.62 & 0.81 & 307 & 230 \\
\hline 14 & 0.98 & 12.2 & 0.78 & 0.72 & 10.5 & 11.4 \\
\hline 15 & 0.97 & 0.80 & 0.93 & 0.81 & 9.6 & 9.8 \\
\hline 16 & 0.91 & 1.27 & 0.72 & 0.94 & 11.2 & 10.8 \\
\hline 17 & 0.90 & 1.78 & 0.75 & 0.86 & 11.9 & 11.5 \\
\hline 18 & 0.85 & 1.16 & 0.79 & 0.74 & 0.70 & 0.018 \\
\hline 19 & 1.14 & 11.0 & 0.99 & 0.95 & 158 & 10.4 \\
\hline 20 & 10.2 & 12.3 & 0.96 & 0.91 & 11.4 & 10.8 \\
\hline 21 & 10.4 & 11.6 & 0.81 & 0.73 & 10.7 & 9.4 \\
\hline SA & 7.11 & 9.84 & 7.63 & 0.77 & 25.0 & 0.24 \\
\hline AZA & 0.10 & 0.48 & 0.13 & 0.01 & 0.25 & 0.012 \\
\hline TPM & 3.02 & 0.61 & 1.11 & 0.37 & 0.25 & 0.010 \\
\hline ZNS & 0.21 & 286.8 & 0.94 & 0.97 & 0.056 & 0.035 \\
\hline phenol & 79.0 & 64.0 & 17.3 & 25.9 & 10.1 & 5.5 \\
\hline
\end{tabular}


${ }^{a}$ Errors in the range of $\pm 5 \%$ of the reported value, from three determinations. ${ }^{b}$ All proteins were recombinant and obtained as described by us previously. ${ }^{10,12,20,21,41,42}$

A number of noteworthy structure-activity relationships (SARs) were identified in this study and are summarized as follows:

\subsubsection{M. tuberculosis $\beta$-CA inhibition: Rv3273}

The activity of the NP library against $\beta$-CA Rv3273 comprised compounds with two distinct inhibition profiles. The first group are diverse in structure and include the tyrosol scaffold $\mathbf{1}$, the carboxylic acids $\mathbf{2}$ and $\mathbf{4}$, their amide analogues $\mathbf{3}$ and $\mathbf{5}$, the 2-chlorophenol derivatives (compounds 6, 20 and 21), the xanthones 9 and 10, endiandrin A 11 and (-)-dihydroguaiaretic acid 13. This group exhibited moderate Rv3273 inhibitory activity with inhibition constants in the range of $8.92-12.1 \mu \mathrm{M}$. This inhibition is greater than that for phenol $\left(\mathrm{K}_{\mathrm{i}}\right.$ of $\left.79 \mu \mathrm{M}\right)$ the core fragment-in-common of this NP library, comparable to that of SA $\left(K_{i}\right.$ of $\left.7.11 \mu \mathrm{M}\right)$ but weaker than the remaining clinically used CAIs $\left(\mathrm{K}_{\mathrm{i}} \mathrm{S}\right.$ of $\left.0.10-3.02 \mu \mathrm{M}\right)$. The second group (compounds 7, 8, 12 and 14-19) showed better Rv3273 inhibitory activity, with $\mathrm{K}_{\mathrm{i}} \mathrm{S}$ in the range of $0.85-1.14 \mu \mathrm{M}$. Compounds 14-19, synthetic amides based on the scaffold present in the fungal NP 4-hydroxy-3-chlorophenylacetamide 5, incorporate (with the exception of 19) an aromatic substituent on the acetamide nitrogen atom. The weaker inhibitors 20 and 21 from the first group discussed above, possessed the same 4-hydroxy-3-chlorophenylacetamide scaffold but with aliphatic moieties substituting this acetamide nitrogen atom. Both the benzylamine (14) and phenethylamine (15-18) derivatives showed good and comparable inhibition activity. Notably the presence of the sulfonamide moiety in $\mathbf{1 8}$ did not improve the Rv3273 CA (or Rv1284 CA, described below 2.2.2) inhibitory activity over the related nonsulfonamide phenolic derivatives (15-17) which is a striking contrast to the $\alpha$-CAs inhibition profile as discussed later (2.2.4). This SAR indicates that phenol and sulfonamide CA active site anchoring groups may be equally efficient for inhibiting $\beta$-CAs, whereas for the $\alpha$-class enzymes the sulfonamide group is far superior. Polyandrocarpamines A $\mathbf{7}$ and B 8, together with endiandrin B 12, also showed submicromolar Rv3273 inhibitory activity $\left(\mathrm{K}_{\mathrm{i}} \mathrm{S}\right.$ of 0.89 $0.92 \mu \mathrm{M})$. It is interesting to note that the stereoisomer of $\mathbf{1 2}$, endiandrin A $\mathbf{1 1}$, was a 10 -fold weaker Rv3273 CA inhibitor compared to 12.

\subsubsection{M. tuberculosis $\beta$-CA inhibition: Rv1284}


The Rv1284 CA was inhibited very weakly by phenol ( $\mathrm{K}_{\mathrm{i}}$ of $\left.64 \mu \mathrm{M}\right)$, the core fragment scaffold of the NP library, while all compounds from the NP library exhibited enhanced enzyme inhibitory activity for this isozyme compared to phenol. As for $\beta$-CA Rv3273, inhibition profiles lay in two distinct groups. The first group includes compounds 2, 4, 5, 7, 9, 14 and 19-21, with $\mathrm{K}_{\mathrm{i}} \mathrm{S}$ of $10.3-12.3 \mu \mathrm{M}$, while the remaining NP compounds (second group) were more effective Rv1284 CA inhibitors with $\mathrm{K}_{\mathrm{i}} \mathrm{s}$ in the range of $0.71-1.78 \mu \mathrm{M}$. The SAR is complex, yet allowed a number of noteworthy observations. For the simple mono- and disubstituted phenols (1-5) when compared to phenol, it was observed that the introduction of the hydroxyethyl moiety in $\mathbf{1}$ or the carboxamide moiety of $\mathbf{3}$ leads to a $\mathbf{7 5}$ fold increase of the Rv1284 CA inhibitory activity. This trend was not followed with the carboxylic acid moiety 2 or the ortho-halogenated derivatives 4 and 5, although a 6-fold increase was observed with 2, 4 and 5. Among the secondary carboxamides 6a,b and 14-21, the benzylamine 14 derivative and the aliphatic derivatives 19-21 showed inhibition of 11-12 $\mu \mathrm{M}$, whereas the phenethylamines 15-18 and the complex scaffolds of $\mathbf{6 a}$ and $\mathbf{6 b}$, were more effective inhibitors, with $\mathrm{K}_{\mathrm{i}} \mathrm{s}$ of $0.71-1.78 \mu \mathrm{M}$. The addition of one $\mathrm{CH}_{2}$ group to $\mathbf{1 4}$ to give phenethyl 15 lead to a 15-fold increase of the Rv1284 inhibitory activity. As noted for Rv3273 the presence of the sulfonamide moiety in $\mathbf{1 8}$ did not improve the Rv1284 CA. Compounds 7 and $\mathbf{8}$ differ by one $\mathrm{CH}_{2}$ group and have a 13-fold difference of inhibitory activity. Compounds $\mathbf{9}$ and $\mathbf{1 0}$ differ by the presence of a $-\mathrm{CH}_{2} \mathrm{OH}$ moiety in $\mathbf{1 0}$ compared to a $-\mathrm{CH}_{3}$ moiety in $\mathbf{9}$, here the difference of Rv1284 inhibitory activity is $\sim 11$-fold. Thus small and simple structural changes have the capacity to impart significant effects of Rv1284 CA inhibitory activity.

\subsubsection{C. albicans and $C$. neoformans $\beta$-CA inhibition}

Phenol was a weak C. albicans Nce103 CA inhibitor, with a $\mathrm{K}_{\mathrm{i}}$ of $17.3 \mu \mathrm{M}$. SA, TPM and ZNS were better inhibitors (2.3-fold, 15.6-fold and 18.4-fold, respectively) while acetazolamide AZA was the most effective sulfonamide CA inhibitor, with a $\mathrm{K}_{\mathrm{i}}$ of $0.13 \mu \mathrm{M}$. The series of phenolic NPs investigated all showed an efficient low micromolar or submicromolar inhibition, with $\mathrm{K}_{\mathrm{i}} \mathrm{S}$ in the range of $0.62-1.10 \mu \mathrm{M}$. The best inhibitor, (-)dihydroguaiaretic acid 13 was 27.9 times a better Nce103 inhibitor compared to phenol, demonstrating that this scaffold (and the structurally related ones present in $\mathbf{1 1}$ and 12) may constitute valuable leads for obtaining even more potent inhibitors of fungal $\beta$-CAs. Phenol also behaved as a weak C. neoformans Can2 inhibitor, with an inhibition constant of $25.9 \mu \mathrm{M}$, 
and similarly to Nce103 the clinically used sulfonamides showed more potent Can2 inhibition, with $\mathrm{K}_{\mathrm{i}} \mathrm{S}$ of $0.01-0.97 \mu \mathrm{M}$. The phenolic NP library showed low to submicromolar inhibition of this enzyme with $\mathrm{K}_{\mathrm{i}} \mathrm{S}$ in the range of $0.72-1.15 \mu \mathrm{M}$. This relatively flat SAR represents up to 36-fold better inhibition of Can2 by the NPs than simple phenol.

\subsubsection{Human $\alpha$-CA Inhibition}

Compounds 7, 14-17, 20 and 21 inhibited human CA I weakly, similarly to phenol $\left(\mathrm{K}_{\mathrm{i}}=10.1\right.$ $\mu \mathrm{M}$ ) with $\mathrm{K}_{\mathrm{i}} \mathrm{s}$ in the range of $9.6-11.9 \mu \mathrm{M}$. Other NPs were weaker inhibitors of this offtarget enzyme with $\mathrm{K}_{\mathrm{i}} \mathrm{S}$ in the range of $158-430 \mu \mathrm{M}$. Compound 18, with a submicromolar $\mathrm{K}_{\mathrm{i}}$ of $0.70 \mu \mathrm{M}$, was a notable exception, albeit consistent with the inclusion of a sulfonamide moiety onto the structure of this semi-synthetic NP derivative, the sulfonamide being a proven effective zinc binding function in $\alpha$-CAs. Compound 18 shows better human CA I inhibitory activity than SA ( $\mathrm{K}_{\mathrm{i}}$ of $25 \mu \mathrm{M}$ ), but is a slightly weaker inhibitor than AZA, TPM and ZNS $\left(\mathrm{K}_{\mathrm{i}} \mathrm{S}\right.$ of $\left.0.056-0.25 \mu \mathrm{M}\right)$.

Human CA II was generally better inhibited by 1-21 than human CA I, yet activity remained in the low micromolar range for many compounds, again similar to that of phenol $\left(\mathrm{K}_{\mathrm{i}}\right.$ of 5.5 $\mu \mathrm{M})$. NPs 5 and 13, whilst better human CA II than human CA I inhibitors, showed very weak human CA II inhibitory activity ( $\mathrm{K}_{\mathrm{i}} \mathrm{S}$ of 131 and $230 \mu \mathrm{M}$, respectively) compared to the remainder of the NP-based library. It is significant to note that minimal structural changes can lead to significant differences of CA inhibitory properties. For example, the carboxylic acid $\mathbf{4}$, while structurally related to amide 5, was a much stronger human CA II inhibitor than 5 (15fold). Also of note is that the more flexible lignan, (-)-dihydroguaiaretic acid 13, showed 19fold weaker human CA II inhibitory activity compared to the more rigid cyclobutane lignans, endiandrins A 11 and B 12, indicating a potential avenue for further SAR exploration. As for human CA I, the most active NP human CA II inhibitor was the sulfonamide $\mathbf{1 8}$ with a $\mathrm{K}_{\mathrm{i}}$ of $18 \mathrm{nM}$, this compound has inhibition comparable to the clinically used drugs AZA and TPM ( $\mathrm{K}_{\mathrm{i}} \mathrm{S}$ of 10 and $12 \mathrm{nM}$, respectively). Compound 18 has been shown earlier by one of our groups to also act as an efficient inhibitor of the bovine enzyme ortholog to human CA II. ${ }^{43}$

\subsection{CA inhibition selectivity profiles}


Selectivity for $\beta$-CAs against $\alpha$-CAs is an important consideration for downstream use of these compounds as chemical probes, for example in vivo studies to evaluate the druggability of the pathogen enzymes. The selectivity ratios of $\beta$-CA inhibition versus $\alpha$-CA I and $\alpha$-CA II inhibition are presented in Tables 2 and 3, respectively. 
Table 2: Selectivity ratios of $K_{i} s$ for $\beta$-CAs compared to human $\alpha$-CA isozyme I for the NPbased library (1-21), known CA inhibitors (SA, AZA, ZNS and TPM) and phenol.

\begin{tabular}{|c|c|c|c|c|}
\hline \multirow[t]{2}{*}{ Compound } & \multicolumn{4}{|c|}{ Selectivity Ratios of $\mathrm{K}_{\mathrm{i}} \mathrm{s}^{a}$} \\
\hline & CA I/Rv3273 & CA I/Rv1284 & CA I/Nce103 & CA I/Can2 \\
\hline 1 & 35.5 & 505.9 & 390.9 & 398.1 \\
\hline 2 & 27.1 & 28.6 & 302.9 & 343.3 \\
\hline 3 & 33.9 & 363.5 & 339.6 & 367.9 \\
\hline 4 & 24.5 & 25.7 & 245.4 & 236.6 \\
\hline 5 & 21.2 & 22.6 & 237.0 & 278.8 \\
\hline $6 a$ & 21.2 & 284.5 & 232.0 & 207.8 \\
\hline $6 b$ & 21.2 & 325.4 & 224.3 & 208.1 \\
\hline 7 & 11.5 & 0.9 & 11.4 & 11.8 \\
\hline 8 & 385.9 & 390.1 & 394.4 & 373.7 \\
\hline 9 & 17.6 & 19.1 & 189.6 & 179.5 \\
\hline 10 & 34.3 & 377.8 & 370.3 & 346.3 \\
\hline 11 & 41.3 & 448.8 & 504.1 & 477.9 \\
\hline 12 & 397.8 & 442.5 & 505.7 & 372.6 \\
\hline 13 & 33.7 & 361.2 & 495.2 & 379.0 \\
\hline 14 & 10.7 & 0.9 & 13.5 & 14.6 \\
\hline 15 & 9.9 & 12.0 & 10.3 & 11.9 \\
\hline 16 & 12.3 & 8.8 & 15.6 & 11.9 \\
\hline 17 & 13.2 & 6.7 & 15.9 & 13.8 \\
\hline 18 & 0.8 & 0.6 & 0.9 & 0.9 \\
\hline 19 & 138.6 & 14.4 & 159.6 & 166.3 \\
\hline 20 & 1.1 & 0.9 & 11.9 & 12.5 \\
\hline 21 & 1.0 & 0.9 & 13.2 & 14.7 \\
\hline
\end{tabular}




\begin{tabular}{lllll} 
SA & 3.5 & 2.5 & 3.3 & 32.5 \\
AZA & 2.5 & 0.5 & 1.9 & 25.0 \\
TPM & 0.1 & 0.4 & 0.2 & 0.7 \\
ZNS & 0.3 & 0.0002 & 0.1 & 0.1 \\
phenol & 0.1 & 0.2 & 0.6 & 0.4 \\
\hline
\end{tabular}

${ }^{a}$ The $\mathrm{K}_{\mathrm{i}}$ ratios are indicative of isozyme selectivity for pathogen CAs in vitro and are calculated as $\mathrm{K}_{\mathrm{i}}$ human CA $\mathrm{I} / \mathrm{K}_{\mathrm{i}} \beta-\mathrm{CA}$

Table 3: Selectivity ratios of $\mathrm{K}_{\mathrm{i}} \mathrm{s}$ for $\beta$-CAs compared to human $\alpha$-CA isozyme II for the NPbased library (1-21), known CA inhibitors (SA, AZA, ZNS and TPM) and phenol.

\begin{tabular}{lllll}
\hline Compound & & \multicolumn{3}{c}{ Selectivity Ratios of $\mathrm{K}_{\mathrm{i}} \mathrm{s}^{a}$} \\
\hline $\mathbf{1}$ & CA II/Rv3273 & CA II/Rv1284 & CA II/Nce103 & CA II/Can2 \\
$\mathbf{2}$ & 0.7 & 10.2 & 7.9 & 8.1 \\
$\mathbf{3}$ & 0.9 & 1.0 & 10.1 & 11.4 \\
$\mathbf{4}$ & 1.2 & 13.2 & 12.3 & 13.3 \\
$\mathbf{5}$ & 0.8 & 0.8 & 8.0 & 7.7 \\
$\mathbf{6 a}$ & 11.7 & 12.5 & 131.0 & 154.1 \\
$\mathbf{6 b}$ & 0.7 & 9.9 & 8.1 & 7.2 \\
$\mathbf{7}$ & 0.7 & 11.3 & 7.5 & 7.2 \\
$\mathbf{8}$ & 10.5 & 0.8 & 10.4 & 10.8 \\
$\mathbf{9}$ & 14.2 & 14.4 & 14.6 & 13.8 \\
$\mathbf{1 0}$ & 0.7 & 0.8 & 7.9 & 7.5 \\
$\mathbf{1 1}$ & 0.8 & 9.3 & 9.1 & 8.5 \\
$\mathbf{1 2}$ & 1.3 & 14.3 & 16.0 & 15.2 \\
\hline
\end{tabular}


13

14

15

16

17

18

19

20

21

SA

AZA

TPM

0.003

ZNS

0.2

0.1

$\begin{array}{lll}0.1 & 0.03 & 0.1\end{array}$

\footnotetext{
${ }^{a}$ The $\mathrm{K}_{\mathrm{i}}$ ratios are indicative of isozyme selectivity for pathogen CAs in vitro and are calculated as $\mathrm{K}_{\mathrm{i}}$ human CA $\mathrm{II} / \mathrm{K}_{\mathrm{i}} \beta-\mathrm{CA}$
}

The clinically used CA inhibitors SA, AZA, TPM and ZNS as well as phenol were less effective inhibitors for the mycobacterial and fungal $\beta$-CA enzymes. The reverse trend was observed for many of the phenolic NPs derivatives reported here, with many exhibiting a marked selectivity for the inhibition of the $\beta$-class CAs over the $\alpha$-CAs, Table 2 and 3 . The selectivity ratios listed in Table 2 show that NP-based phenols 1-13 and 19 were up to several hundred-fold selective for pathogen CAs over human CA I and thus may represent leads for better discriminating the inhibition of $\beta$-CAs from pathogens. Clearly, the synthetic NP based phenols 14-18, 20 and 21 were less effective in this respect, since they showed a maximum of 15-fold selectivity for fungal CAs over human CA I, and no selectivity for mycobacterial CAs over human CA I. Interestingly, almost all compound from the NP-based library (1-21) discriminated between the fungal CAs and human CA II by one order of magnitude better than between the mycobacterial CAs and human CA II. All phenols of the library (with the 
exception of the phenolic sulfonamide 18 discussed next) were one to two orders of magnitude selective for fungal CAs over human CA II. Phenols 5, 7, 8, 12-17 and 19 were an order of magnitude selective for inhibition of Rv3273 $\beta$-CA over CA II, while a different group of phenols $(\mathbf{1}, 3,5,6,8,10-13$ and 15) were an order of magnitude selective for inhibition of Rv1284 $\beta$-CA over CA II, Table 3. The best performing compounds in this analysis are 13 and 5. (-)-Dihydroguaiaretic acid (compound 13), was a sub-micromolar $\beta$-CA inhibitor with up to 495-fold selectivity over human CA I and 371-fold selectivity over human CA II. Compared to the classical CA inhibitors, these $\beta / \alpha$ selectivity profiles are quite remarkable. Compound 5 was identified as a low-micromolar inhibitor of the fungal CAs where it displayed 130- to 280-fold selectivity over the two human CAs.

The synthetic compound 18, a phenolic sulfonamide, was an outlier to all trends described so far with high selectivity for human CA II. As the only sulfonamide of the series of investigated NP-based compounds, 18 showed comparable inhibition of the pathogen CAs compared to its structural congeners $(\mathbf{1 4 - 1 7}, \mathbf{1 9 - 2 1})$, and indeed any other compound from the library lacking the sulfonamide moiety. This SAR implies that $\beta$-CA inhibition may be mediated by both the classical sulfonamide zinc binding group as well as the phenolic moiety. The situation is very different for the $\alpha$-CAs, where phenolic compounds were generally 1-2 orders of magnitude less efficient $\alpha$-CA inhibitors than classical sulfonamide or sulfamate inhibitors. ${ }^{44-47}$ The consistency of this observation across four distinct $\beta$-CAs provides a compelling opportunity to explore the phenol scaffold in the development of potent and selective inhibitors for the $\beta$-family of CAs.

\subsection{Structural analysis of ligand-protein interactions}

Previously, two structural entities not directly interacting with the active site zinc ion have been reported as inhibitors for $\alpha$-CAs, phenol ${ }^{19}$ and coumarins. ${ }^{17,48}$ Intriguingly, the crystal structure of ligand-bound human CA II using the naturally occurring coumarin derivative 6(1-S-hydroxy-3-methylbutyl)-7-methoxy-2H-chromen-2-one revealed that the coumarin scaffold had been transformed into the compound CIN (Figure 1) through ring opening thus establishing a phenol moiety. With the NP-based library in this study, we therefore probed a variety of structurally different phenol compounds to assess the structure-activity relationships of this chemotype in the context of CAs. 
In order to determine how the phenolic-based NPs 1-21 might bind or interact with CAs, soaking and co-crystallization studies were undertaken with the readily available protein human CA II. The identification of unique CA binding for any of the NPs might offer possibilities for future rational drug discovery design and development. To date none of the NPs have yielded co-crystals with CAs suitable for X-ray diffraction studies, except for compound 18 and $\mathbf{6 b}$. There are numerous known structures of CA II:sulfonamide adducts, but compound 18 is the only one reported to date to possess two CA pharmacophores that have been correlated with CA inhibition: the sulfonamide moiety and the phenol moiety. The adduct of compound $\mathbf{1 8}$ and human CA II formed good quality crystals that allowed us to determine its three-dimensional structure at $1.8 \AA$. As expected, the binding mode of the sulfonamide moiety of $\mathbf{1 8}$ interacting with the $\mathrm{Zn}^{2+}$ ion in the catalytic site of human CA II is invariant when compared to other sulfonamide/sulfamate-containing ligands such as AZA or TPM (Figure 5, left). No conformational rearrangements of protein residues are observed in the ligand-bound structure as compared to apo-human CA II. Determined by the shape of 18, the ligand is positioned nearly centred with its long axis parallel to the vertical axis of the active site cleft, thus placing the phenol moiety at the surface of the protein fully exposed to solvent. Water is fully excluded from the active site, and only found at the surface opening of the cleft, where the amide nitrogen and the phenol-OH of $\mathbf{1 8}$ maintain hydrogen bonds to several water molecules. The phenol moiety of $\mathbf{1 8}$ exhibits hydrophobic interactions with Phe130 and Gly131 in the upper part of the active site cleft, thereby placing it in a similar position as the phenol moiety of $\mathbf{C I N}$.

From the panel of non-sulfonamide/sulfamate compounds in the current library, ligand-bound crystals were obtained for human CA II in complex with $\mathbf{6 b}$, with diffraction up to $2.0 \AA$. Like compound $\mathbf{1 8}, \mathbf{6 b}$ possesses a rather elongated shape, and thus fits the layout of the active site cleft of human CA II (Figure 5, right). It was anticipated that the phenol moiety of $\mathbf{6 b}$ would play a role in the ligand binding mechanism, and was therefore expected to bind close to the catalytic zinc ion in the space previously determined in the CA II:phenol complex. ${ }^{19}$ Surprisingly, the crystal structure revealed that it is the methyl ester distal to the phenol moiety of $\mathbf{6 b}$ that sits in the inner part of the active site cleft. The ester carbonyl of $\mathbf{6 b}$ interacts with a zinc-bound water molecule and is further engaged in a hydrogen bond donated by the backbone amide group of Thr198. In this crystal structure, the electron density of the inhibitor is well defined, allowing unambiguous placement of the ligand. This is a totally new binding mode to CAs. Furthermore, the binding is similar to that of the polyamines, a recently described new chemotype for the CA inhibition. ${ }^{49}$ Indeed, spermine 
anchors to the zinc-coordinated water (hydroxide ion) from the CA active site through one of its primary amine moieties exactly as the methyl ester from $\mathbf{6 b}$ reported here does. Thus, we now provide evidence through a third example (after phenol and spermine) that anchoring to the non-protein zinc ligand in the CA active site may be a valid mechanism to inhibit carbonic anhydrases in the low micromolar range. The binding of compound $\mathbf{6 b}$ to the active site is further supported by a number of hydrogen bonds and van der Waals interactions with active site residues and solvent molecules. The electron density clearly indicated two alternate conformations for the phenol moiety of $\mathbf{6 b}$ (rotation of $180^{\circ}$ around the vertical phenol axis), thus giving rise to the chloro substituent appearing on both sides of the phenolic hydroxyl group.

Figure 5. Crystal structures of human CA II in complex with compound 18 (a) and compound 6b (b). Shown are the ligand conformations in the active site, as well as residue side chains involved in ligand interactions and solvent molecules (water as red spheres, glycerol as stick model). The catalytic zinc ion is coloured magenta. The original $F_{0}-F_{c}$ difference density is contoured in green at $2 \sigma$, the final $2 \mathrm{~F}_{0}-\mathrm{F}_{\mathrm{c}}$ density is contoured in blue at $1 \sigma$. Figure prepared with PyMol. ${ }^{40}$

(c) The ligand-protein interactions are illustrated schematically with compound $\mathbf{1 8}$ (left) and compound 6b (right). Protein residues are shown in grey; hydrogen bond interactions are shown as dotted lines, van der Waals interactions as dashed lines. Distances are given in $\AA$. For compound $\mathbf{6 b}$, two conformations of the phenol moiety are observed, giving rise to the appearance of the chloro substituent on both sides of the phenolic hydroxyl group; the refined occupancies for both positions are noted at each position.

a) 


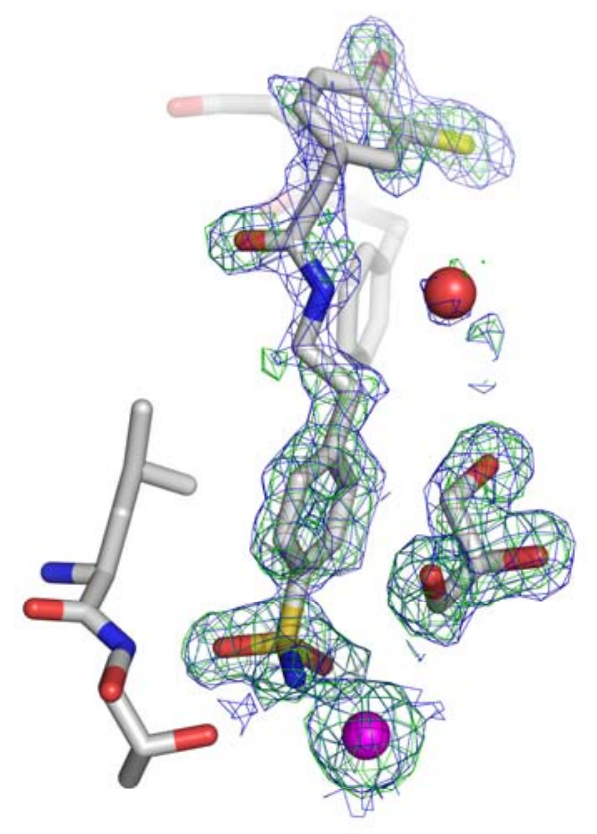

b)

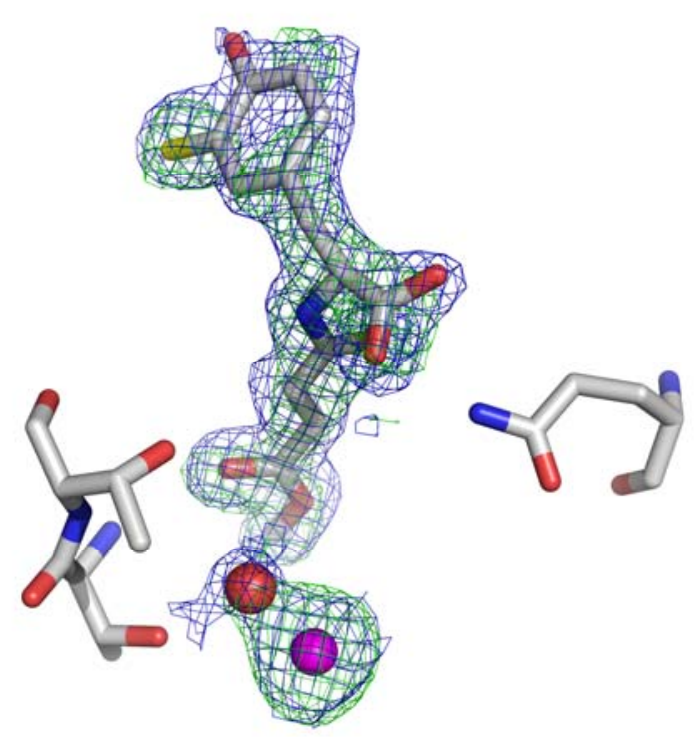

c) 

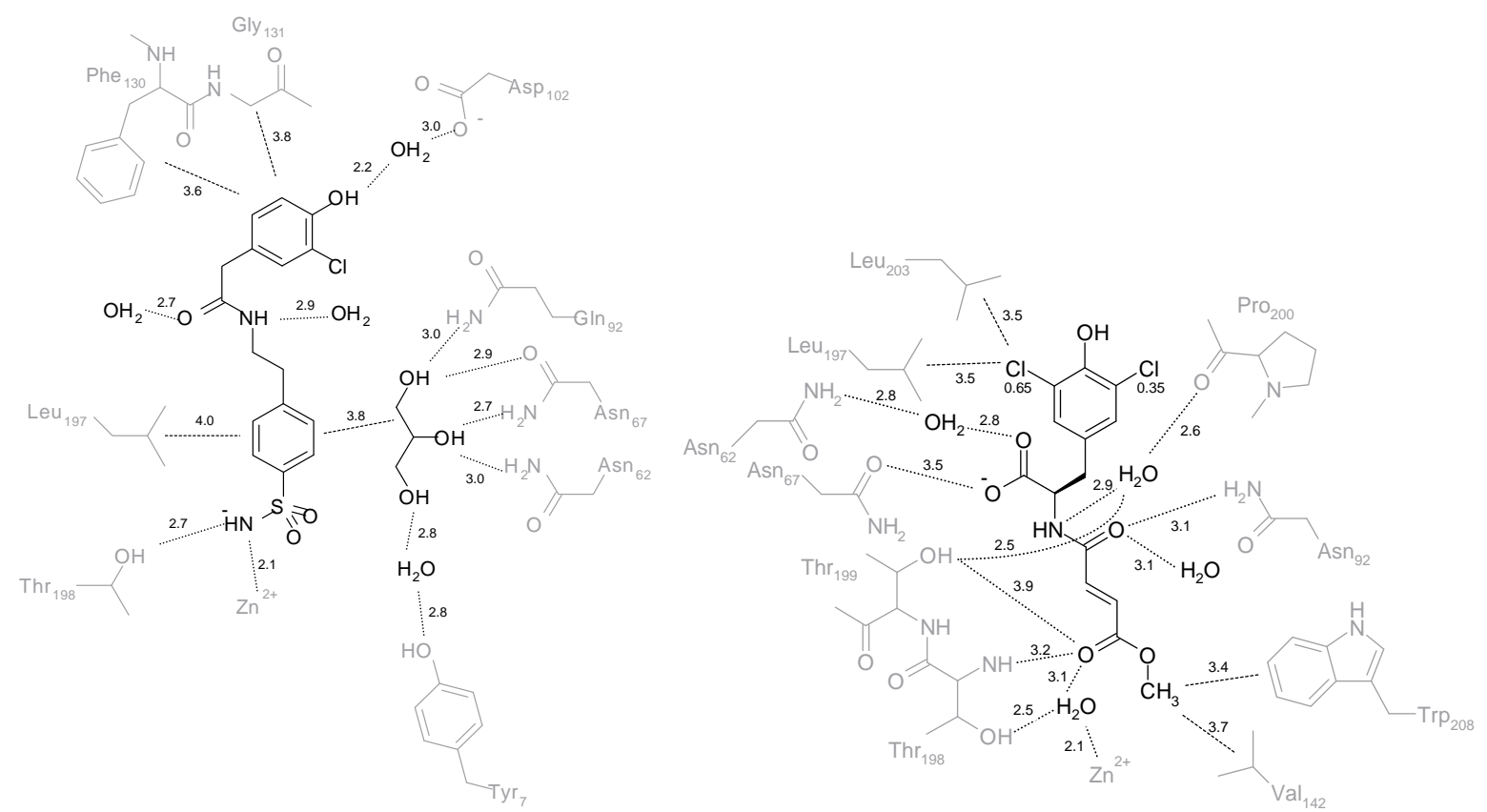

A comparison of available structures of phenolic compounds with CA II (Figure 6) also highlights that the phenol chemotype presents a useful feature providing stabilising interactions with hydrophobic areas of the active site cleft, but there is considerable variation in the actual position of the phenol in the cleft, depending on the availability of other functional groups within the individual phenolic compounds.

Figure 6. Superposition of phenolic ligands in complex with human CA II. Compound $\mathbf{6 b}$ is coloured yellow, cinnamic acid CIN (PDB accession code 3F8E) is coloured purple, and phenol is shown in magenta. The CA II:phenol structure is a reconstruction based on Nair et al. ${ }^{19}$ as the structure was not deposited in the PDB. The colour code of the protein surface indicates surface electrostatics (red: acidic, blue: basic); the active site zinc ion is shown as turquoise sphere. Figure prepared with PyMol. ${ }^{50}$

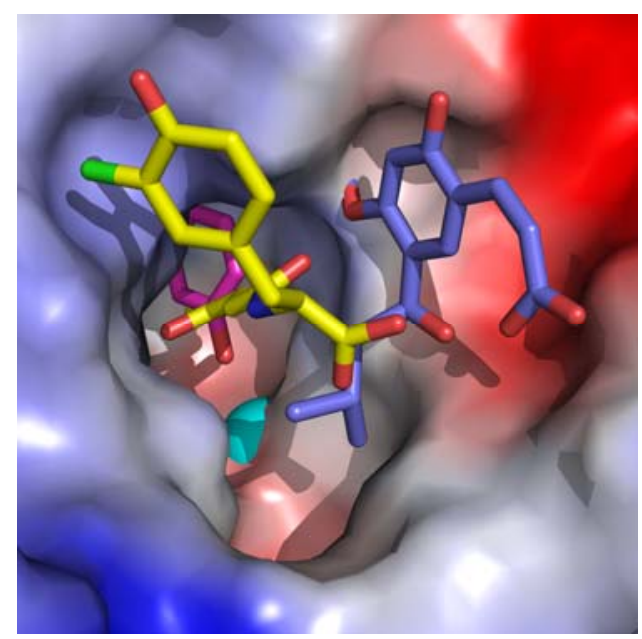


We have attempted to crystallize Can2, Nce103, Rv3273 and Rv1284 enzymes in the presence of various inhibitors, including the NP-based phenols, so far without success. A caveat exists when using human CA II as a prototype for structural investigation of the mycobacterial and fungal CAs. While the enzymes belonging to the $\alpha$ - and $\beta$-class of CAs have in common the existence of an active site zinc ion, there are considerable structural differences. Firstly, all known $\beta$-CAs exist as dimers, whereas $\alpha$-CAs are monomeric enzymes, except CA IX which is a dimer. ${ }^{51}$ The catalytically important residues in the active site of $\beta$-CAs are provided exclusively from one monomer, but access to the catalytic centre may be constituted by residues from both monomers, i.e. assessment of the active site cleft requires analysis of the functional dimer, Figure 7. No structural information is available for Rv3273, but the crystal structure of Rv1284 has been reported. ${ }^{22}$ Importantly, the active site cleft of Rv1284 is extremely small with an accessible surface volume of only about $7 \AA^{3}$ (for comparison: human CA II ca. $100 \AA^{3}$, C. albicans Nce103 ca. $40 \AA^{3}$ ). It is therefore unlikely that the compounds tested in the current library can adopt a binding mode similar to the one seen in human CA II, due to their spatial extension. It also seems unlikely that the phenolic hydroxyl group directly interacts with the active site zinc of the pathogen CAs.

Figure 7. Comparison of accessible surface volumes of the active sites of $M$. tuberculosis Rv1284 (left; PDB accession code 1ylk), C. albicans Nce103 (middle; PDB accession code 3eyx), and human CA II (right; PDB accession code 3NB5). The individual monomers of the dimeric $\beta$-CAs are coloured in green and blue, respectively. The catalytic zinc ion is shown in magenta. Figure prepared with PyMol. ${ }^{50}$
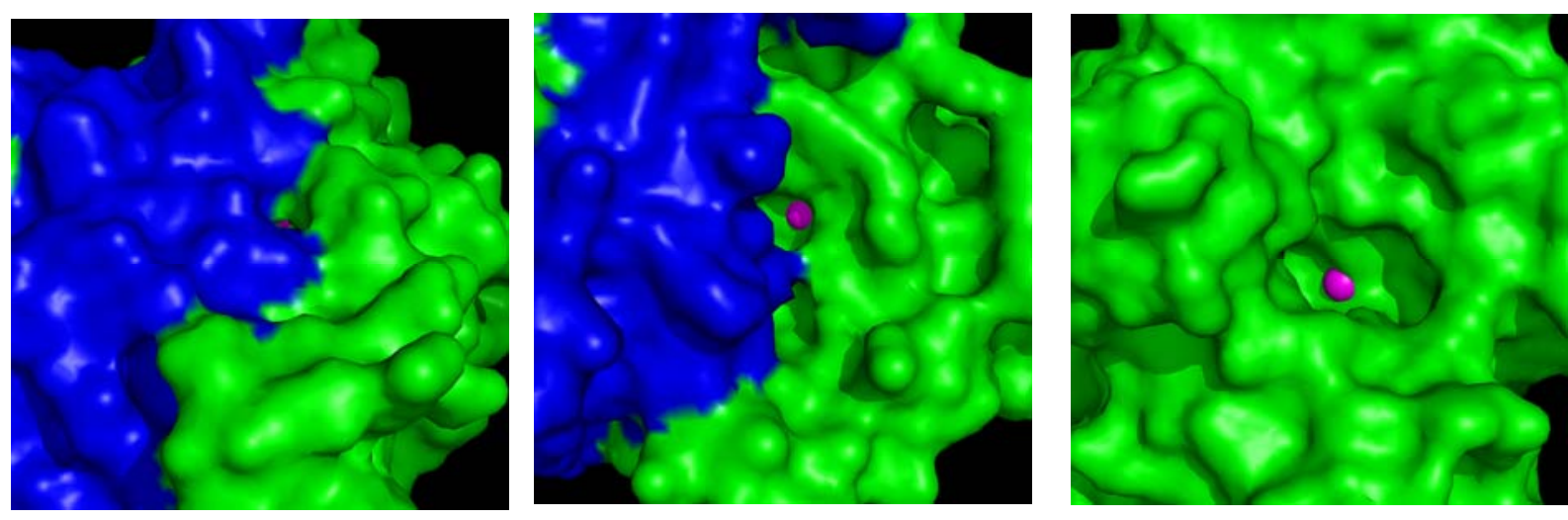

Two mechanisms may explain the inhibitory effects of compounds identified in this study. It is possible that the compounds cause either monomerisation or considerable conformational 
changes in the access area to the active site. The latter is sealed by the N-terminal 'arm' of the second monomer. The implications of this structural feature as a regulatory domain ${ }^{52}$ and possible gate-keeper for access to the ligand binding site ${ }^{53}$ in Nce103 and Can2, respectively, have previously been recognised. The 'arm' consists of helices $\alpha 1-\alpha 4$ in case of the fungal CAs, and it seems possible that this subdomain swings away to allow access to active site. In the mycobacterial Rv1284, however, the proline sequence PLPMPSKH from the second monomer covers the access area to the active site. Since proline-rich sequences are typically involved in protein-protein interactions, it is tempting to speculate about involvement of other proteins in the regulation of Rv1284. Additionally, the serine residue of the proline-rich sequence may potentially be phosphorylated and trigger a conformational change of the 'arm' of Rv1284 that may widen access to the active site (precedence of such mechanism e.g. in RNA polymerase $\mathrm{II}^{54}$ ). A retraction of the $\mathrm{N}$-terminal arm by the second monomer would reveal a shallow elongated groove on the surface extending from the active site (Figure 8). This model was obtained by manual superposition using the zinc binding mode of compound 6b as observed in the crystal structure of CA II:6b and the reported structure of Rv1284 (PDB code 1ylk). Minor adjustments to the bond angles of rotatable bonds in $\mathbf{6 b}$ were performed manually to achieve reasonable interactions of the compound with the protein. Here, ligands such as $\mathbf{6 b}$ would be able to bind on the surface of the protein and appropriate functional groups can interact with residues or the zinc ion in the active site. In such scenario, the phenol chemotype, in addition to a functional group that engages in coordination of the active site metal, may play a major role. Such a mechanism is supported by the inhibitory effects of the sulfonamide-containing compound $\mathbf{1 8}$, assuming that the sulfonamide moiety indeed interacts with the active site metal. These suggestions are in agreement with the observations made for Can2 and benzolamide. ${ }^{53}$

Figure 8. Putative ligand binding mode of compound $6 \mathbf{b}$ on mycobacterial Rv1284 (PDB accession code 1ylk). After removal of the N-terminal 'arm', a shallow binding groove is revealed on one monomer that presents sufficient shape complementarity to allow interactions with the ligand. The colour code of the protein surface indicates surface electrostatics (red: acidic, blue: basic); the active site zinc ion is shown as magenta sphere. Figure prepared with PyMol. ${ }^{50}$ 


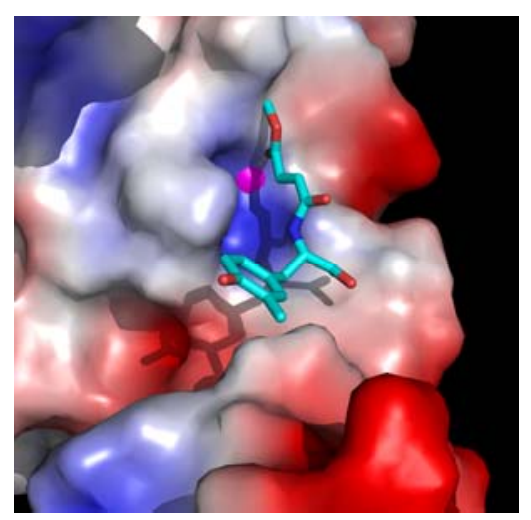

\section{Conclusions}

We have investigated the enzyme inhibition characteristics of a phenolic-based NP library (compounds 1-21) against a panel of CAs encompassing the human $\alpha$-CAs I and II, the pathogenic $M$. tuberculosis $\beta$-CAs and fungal enzymes from C. albicans and C. neoformans. This is the first study in which $\beta$-CAs have been investigated for their interaction with compounds containing the phenol motif, a novel chemotype for CA inhibition. Clinically used sulfonamides are low nanomolar human CA II inhibitors and inhibit human CA I and these $\beta$ CA enzymes only in the micromolar range. In contrast, many of the phenols had submicromolar affinity for the pathogen enzymes and significantly 1-2 orders of magnitude selectivity for the inhibition of the $\beta$-CA class over both human $\alpha$-CAs. The two best performing compounds, 5 and 13, preferentially inhibited fungal CAs over human CAs with selectivities more than two orders of magnitude, and therefore represent novel leads for specific probes of $\beta$-CAs from pathogens. These compounds provide the first non-classical CA inhibitors with this important selectivity characteristic towards pathogen over host enzymes.

Structural characterisation of the compounds used in this study in complex with human CA II was hampered by the low yield of ligand-bound crystals. The complex of compound 18, a sulfonamide derivative of compound 15, with human CA II could be investigated crystallographically. We also obtained a crystal structure of compound $\mathbf{6 b}$ with human CA II, that revealed a novel binding mode for $\alpha$-CAs whereby a methyl ester interacts with a zinc-bound water molecule the active site. The phenol moiety of $\mathbf{6 b}$, similarly to compound 18 or $\mathbf{C I N}$, is located in the upper part of the active site cleft. The zinc coordination observed with CA II:6b is reminiscent of the CA II:phenol complex observed by Christianson and colleagues ${ }^{19}$ where a zinc-bound water molecule presents the contact for the 
active site ligand. Crystal structures of pathogen CAs in complex with compounds such as $\mathbf{6 b}$ or $\mathbf{1 8}$ will certainly be of enormous help in dissecting their molecular mechanisms.

This study provides the compelling indication of the usefulness of novel chemotypes such as phenols, especially for targetting both $\alpha$ - and $\beta$-CAs. We anticipate that this study will provide a valuable platform to guide the development of future CA inhibitors comprising novel chemotypes with improved activity and drug-like properties for targetting pathogen CA enzymes. Such compounds may be useful for the development of chemical probes and the design of antifungal and antimycobacterial agents, representing a new scientific opportunity with a novel mechanism of action towards treating infections for which multidrug resistance is a current major health concern.

\section{Experimental}

\subsection{Chemistry}

The isolation of NPs 1-13 has been described earlier. ${ }^{30,33-38,43}$ The synthesis of NP analogues 14-21 was achieved by the reaction of 3-chloro-4-hydroxyphenylacetic acid (4) with a panel of eight different primary amines using 1-ethyl-3-(3'-dimethylaminopropyl)-carbodiimide hydrochloride and 4-dimethylaminopyridine in $\mathrm{CH}_{3} \mathrm{CN}$ at room temperature as described earlier. $^{39}$ All compounds were analyzed for purity by $\mathrm{C}_{18} \mu \mathrm{PLC}$ and shown to be $>95 \%$. This microfluidic purity analysis methodology has been previously reported. ${ }^{55}(+)$-Xylariamide A (6b), the enantiomer of the naturally occurring fungal natural product, was produced by $\mathrm{N}, \mathrm{O}$ bis(trimethylsilyl)acetamide induced coupling of 3-chloro-L-tyrosine with (E)-but-2-enedioic acid 2,5-dioxo-pyrrolidin-1-yl ester methyl ester in DMF at $55^{\circ} \mathrm{C} .{ }^{56}$

\subsection{CA inhibition}

An Applied Photophysics stopped-flow instrument has been used for assaying the CA catalyzed $\mathrm{CO}_{2}$ hydration activity. ${ }^{40}$ Phenol red (at a concentration of $0.2 \mathrm{mM}$ ) has been used as indicator, working at the absorbance maximum of $557 \mathrm{~nm}$, with $20 \mathrm{mM}$ Hepes (pH 7.5 for the $\alpha$-CAs) or TRIS (pH 8.3 for the $\beta$-CAs) as buffers, and $20 \mathrm{mM} \mathrm{Na}_{2} \mathrm{SO}_{4}$ (for maintaining constant the ionic strength), following the initial rates of the CA-catalyzed $\mathrm{CO}_{2}$ hydration reaction for a period of $10-100 \mathrm{~s}$. The $\mathrm{CO}_{2}$ concentrations ranged from 1.7 to $17 \mathrm{mM}$ for the determination of the kinetic parameters and inhibition constants. For each inhibitor at least six traces of the initial $5-10 \%$ of the reaction have been used for determining the initial velocity. The uncatalyzed rates were determined in the same manner and subtracted from the total 
observed rates. Stock solutions of inhibitor $(0.1 \mathrm{mM})$ were prepared in distilled-deionized water and dilutions up to $0.01 \mathrm{nM}$ were done thereafter with distilled-deionized water. Inhibitor and enzyme solutions were preincubated together for $15 \mathrm{~min}$ at room temperature (prior to assay, in order to allow for the formation of the enzyme-inhibitor complex or for the eventual active site mediated hydrolysis of the inhibitor. The inhibition constants were obtained by non-linear least-squares methods using PRISM 3, and represent the mean from at least three different determinations. Sulfonamides used as standards in the enzymatic assay were from Sigma-Aldrich (Milan, Italy). Human, mycobacterial and fungal CAs were recombinant proteins prepared and purified as described by us earlier. ${ }^{10,12,20,21,41,42}$

\subsection{Protein X-ray crystallography}

Bacterial expression of human recombinant carbonic anhydrase II and crystallisation protocols have been described earlier. ${ }^{57}$ Typically, ligand-bound crystals were obtained by cocrystallisation with a concentration of $10 \mathrm{mM}$ ligand (added from a $60 \mathrm{mM}$ stock solution in $\mathrm{MeOH})$. In cases where no crystal formation was observed by co-crystallisation, soaking of CA II crystals with $15 \mathrm{mM}$ ligand (supplied from $60 \mathrm{mM}$ stock solution in $\mathrm{MeOH}$ ) and under saturating conditions (ligand supplied as solid in the soaking droplet) was attempted. A concentration of $10 \mathrm{mM}$ ligand in the cryoprotectant (25\% glycerol in mother liquor) was maintained. X-ray diffraction of the adduct of human CA II with library compounds were obtained in-house (Rigaku MicroMax-007HF with VariMax optics and R-Axis IV++ detector), and at the Australian Synchrotron beam line MX1 (equipped with an ADSC Quantum CCD detector). The data were processed with MOSFLM ${ }^{58}$ and SCALA from the CCP4 program suite. ${ }^{59}$ The structures were determined using difference Fourier techniques and refined with $\mathrm{CNS}^{60}$ The structures were determined using difference Fourier techniques and refined with CNS (compound 18) and Phenix (compound 6b) ${ }^{61}$ Ligand topology was generated with PRODRG ${ }^{62}$ and manual model building was performed with $0 .{ }^{63}$ For data collection and refinement statistics, please see the supplementary information. Coordinates and structure factors have been deposited with the PDB (accession code 3NB5 and 3P4V).

\section{Acknowledgements}

This research was financed in part by the Australian Research Council (Grant number DP0877554 to S.-A.P.), a grant of the $6^{\text {th }}$ Framework Programme (FP) of the European Union (DeZnIT project), and by a grant of the $7^{\text {th }}$ FP of EU (Metoxia project). The support of this 
study by a Program Grant from the Australian Synchrotron to A.H. is gratefully acknowledged.

\section{Supporting Information Available}

Protein X-ray crystallography data collection and refinement statistics of the CA II:ligand complexes. This material is available free of charge via the Internet at http://pubs.acs.org.

\section{References}

1. Wise, R. The worldwide threat of antimicrobial resistance. Current Science 2008, 95, 181-187.

2. Dye, C. Doomsday postponed? Preventing and reversing epidemics of drug-resistant tuberculosis. Nat. Rev. Microbiol. 2009, 7, 81-87.

3. Showalter, H. D. H.; Denny, W. A. A roadmap for drug discovery and its translation to small molecule agents in clinical development for tuberculosis treatment. Tuberculosis 2008, 88, S3-S17.

4. Fridkin, S. K.; Jarvis, W. R. Epidemiology of nosocomial fungal infections. Clin. Microbiol. Rev. 1996, 9, 499-511.

5. Cannon, R. D.; Lamping, E.; Holmes, A. R.; Niimi, K.; Tanabe, K.; Niimi, M.; Monk, B. C. Candida albicans drug resistance another way to cope with stress. Microbiology 2007, 153, 3211-3217.

6. Perfect, John R.; Dismukes, William E.; Dromer, F.; Goldman, David L.; Graybill, John R.; Hamill, Richard J.; Harrison, Thomas S.; Larsen, Robert A.; Lortholary, O.; Nguyen, M.-H.; Pappas, Peter G.; Powderly, William G.; Singh, N.; Sobel, Jack D.; Sorrell, Tania C. Clinical Practice Guidelines for the Management of Cryptococcal Disease: 2010 Update by the Infectious Diseases Society of America. Clin. Infect. Dis. 2010, 50, 291-322.

7. Supuran, C. T. Carbonic anhydrases: novel therapeutic applications for inhibitors and activators. Nat. Rev. Drug Discov. 2008, 7, 168-181.

8. Smith, K. S.; Ferry, J. G. Prokaryotic carbonic anhydrases. FEMS Microbiol. Rev. 2000, 24, 335-366.

9. Nishimori, I.; Minakuchi, T.; Kohsaki, T.; Onishi, S.; Takeuchi, H.; Vullo, D.; Scozzafava, A.; Supuran, C. T. Carbonic anhydrase inhibitors: The [beta]-carbonic anhydrase from Helicobacter pylori is a new target for sulfonamide and sulfamate inhibitors. Bioorg. Med. Chem. Lett. 2007, 17, 3585-3594. 
10. Nishimori, I.; Onishi, S.; Takeuchi, H.; Supuran, C. T. The [alpha] and [beta] Classes Carbonic Anhydrases from Helicobacter pylori as Novel Drug Targets. Curr. Pharm. Des. 2008, 14, 622-630.

11. Isik, S.; Kockar, F.; Aydin, M.; Arslan, O.; Guler, O. O.; Innocenti, A.; Scozzafava, A.; Supuran, C. T. Carbonic anhydrase inhibitors: Inhibition of the [beta]-class enzyme from the yeast Saccharomyces cerevisiae with sulfonamides and sulfamates. Bioorg. Med. Chem. 2009, 17, 1158-1163.

12. Innocenti, A.; Mühlschlegel, F. A.; Hall, R. A.; Steegborn, C.; Scozzafava, A.; Supuran, C. T. Carbonic anhydrase inhibitors: Inhibition of the [beta]-class enzymes from the fungal pathogens Candida albicans and Cryptococcus neoformans with simple anions. Bioorg. Med. Chem. Lett. 2008, 18, 5066-5070.

13. Innocenti, A.; Hall, R. A.; Schlicker, C.; Mühlschlegel, F. A.; Supuran, C. T. Carbonic anhydrase inhibitors. Inhibition of the [beta]-class enzymes from the fungal pathogens Candida albicans and Cryptococcus neoformans with aliphatic and aromatic carboxylates. Bioorg. Med. Chem. 2009, 17, 2654-2657.

14. Innocenti, A.; Hall, R. A.; Schlicker, C.; Scozzafava, A.; Steegborn, C.; Mühlschlegel, F. A.; Supuran, C. T. Carbonic anhydrase inhibitors. Inhibition and homology modeling studies of the fungal [beta]-carbonic anhydrase from Candida albicans with sulfonamides. Bioorg. Med. Chem. 2009, 17, 4503-4509.

15. Joseph, P.; Turtaut, F.; Ouahrani-Bettache, S.; Montero, J.-L.; Nishimori, I.; Minakuchi, T.; Vullo, D.; Scozzafava, A.; Kolhler, S.; Winum, J.-Y.; Supuran, C. T. Cloning, Characterization, and Inhibition Studies of a $\beta$-Carbonic Anhydrase from Brucella suis. $J$. Med. Chem. 2010, 53, 2277-2285.

16. Vullo, D.; Nishimori, I.; Scozzafava, A.; Köhler, S.; Winum, J.-Y.; Supuran, C. T. Inhibition studies of a [beta]-carbonic anhydrase from Brucella suis with a series of water soluble glycosyl sulfanilamides. Bioorg. Med. Chem. Lett. 2010, 20, 2178-2182.

17. Maresca, A.; Temperini, C.; Vu, H.; Pham, N. B.; Poulsen, S.-A.; Scozzafava, A.; Quinn, R. J.; Supuran, C. T. Non-zinc mediated inhibition of carbonic anhydrases: Coumarins are a new class of suicide inhibitors. J. Am. Chem. Soc. 2009, 131, 3057-3062.

18. Parkkila, S.; Innocenti, A.; Kallio, H.; Hilvo, M.; Scozzafava, A.; Supuran, C. T. The protein tyrosine kinase inhibitors imatinib and nilotinib strongly inhibit several mammalian [alpha]-carbonic anhydrase isoforms. Bioorg. Med. Chem. Lett. 2009, 19, 4102-4106. 
19. Nair, S. K.; Ludwig, P. A.; Christianson, D. W. Two-Site Binding of Phenol in the Active Site of Human Carbonic Anhydrase II: Structural Implications for Substrate Association. J. Am. Chem. Soc. 1994, 116, 3659-3660.

20. Nishimori, I.; Minakuchi, T.; Vullo, D.; Scozzafava, A.; Innocenti, A.; Supuran, C. T. Carbonic Anhydrase Inhibitors. Cloning, Characterization, and Inhibition Studies of a New $\beta$ Carbonic Anhydrase from Mycobacterium tuberculosis. J. Med. Chem. 2009, 52, 3116-3120.

21. Minakuchi, T.; Nishimori, I.; Vullo, D.; Scozzafava, A.; Supuran, C. T. Molecular Cloning, Characterization, and Inhibition Studies of the Rv1284 $\beta$-Carbonic Anhydrase from Mycobacterium tuberculosis with Sulfonamides and a Sulfamate. J. Med. Chem. 2009, 52, 2226-2232.

22. Covarrubias, S. A.; Larsson, A. M.; Högbom, M.; Lindberg, J.; Bergfors, T.; Björkelid, C.; Mowbray, S. L.; Unge, T.; Jones, T. A. Structure and function of carbonic anhydrases from Mycobacterium tuberculosis. J. Biol. Chem. 2005, 280, 18782-18789.

23. Amoroso, G.; Morell-Avrahov, L.; Müller, D.; Klug, K.; Sültemeyer, D. The gene NCE103 (YNL036w) from Saccharomyces cerevisiae encodes a functional carbonic anhydrase and its transcription is regulated by the concentration of inorganic carbon in the medium. Mol. Microbiol. 2005, 56, 549-558.

24. Bahn, Y. S.; Cox, G. M.; Perfect, J. R.; Heitman, J. Carbonic anhydrase and $\mathrm{CO}_{2}$ sensing during Cryptococcus neoformans growth, differentiation, and virulence. Curr. Biol. 2005, 15, 2013-2020.

25. Sassetti, C. M.; Boyd, D. H.; Rubin, E. J. Genes required for mycobacterial growth defined by high density mutagenesis. Mol Microbiol. 2003, 48, 77-84.

26. Sassetti, C. M.; Boyd, D. H.; Rubin, E. J. Comprehensive identification of conditionally essential genes in mycobacteria. Proc. Natl. Acad. Sci. USA 2001, 98, $12712-$ 12717.

27. Clark, D.; Rowlett, R. S.; Coleman, J. R.; Klessig, D. F. Complementation of the yeast deletion mutant DeltaNCE103 by members of the beta class of carbonic anhydrases is dependent on carbonic anhydrase activity rather than on antioxidant activity. Biochem. J. 2004, 379, 609-615.

28. Granger, D. L.; Perfect, J. R.; Durack, D. T. Virulence of Cryptococcus neoformans. Regulation of capsule synthesis by carbon dioxide. J Clin Invest. 1985, 76, 508-516.

29. Davis, R. A.; Innocenti, A.; Poulsen, S.-A.; Supuran, C. T. Carbonic anhydrase inhibitors. Identification of selective inhibitors of the human mitochondrial isozymes VA and 
VB over the cytosolic isozymes I and II from a natural product-based phenolic library. Bioorg. Med. Chem. 2010, 18, 14-18.

30. Davis, R. A.; Watters, D.; Healy, P. C. The isolation and synthesis of 3-chloro-4hydroxyphenylacetamide produced by a plant-associated microfungus of the genus Xylaria. Tetrahedron Lett. 2005, 46, 919-921.

31. Wahle, K.; Caruso, D.; Ochoa, J.; Quiles, J. Olive oil and modulation of cell signaling in disease prevention. Lipids 2004, 39, 1223-1231.

32. Fu, G.; Pang, H.; Wong, Y. Naturally Occurring Phenylethanoid Glycosides: Potential Leads for New Therapeutics. Curr. Med. Chem. 2008, 15, 2592-2613.

33. Davis, R. A. Isolation and Structure Elucidation of the New Fungal Metabolite (-)Xylariamide A. J. Nat. Prod. 2005, 68, 769-772.

34. Davis, R. A.; Baron, P. S.; Neve, J. E.; Cullinane, C. A microwave-assisted stereoselective synthesis of polyandrocarpamines A and B. Tetrahedron Lett. 2009, 50, 880882.

35. Davis, R. A.; Aalbersberg, W.; Meo, S.; Moreira da Rocha, R.; Ireland, C. M. The isolation and synthesis of polyandrocarpamines A and B. Two new 2-aminoimidazolone compounds from the Fijian ascidian, Polyandrocarpa sp. Tetrahedron 2002, 58, 3263-3269.

36. Healy, P. C.; Hocking, A.; Tran-Dinh, N.; Pitt, J. I.; Shivas, R. G.; Mitchell, J. K.; Kotiw, M.; Davis, R. A. Xanthones from a microfungus of the genus Xylaria. Phytochemistry 2004, 65, 2373-2378.

37. Davis, R. A.; Carroll, A. R.; Duffy, S.; Avery, V. M.; Guymer, G. P.; Forster, P. I.; Quinn, R. J. Endiandrin A, a Potent Glucocorticoid Receptor Binder Isolated from the Australian Plant Endiandra anthropophagorum. J. Nat. Prod. 2007, 70, 1118-1121.

38. Davis, R. A.; Barnes, E. C.; Longden, J.; Avery, V. M.; Healy, P. C. Isolation, structure elucidation and cytotoxic evaluation of endiandrin B from the Australian rainforest plant Endiandra anthropophagorum. Bioorg. Med. Chem. 2009, 17, 1387-1392.

39. Davis, R. A.; Pierens, G. K.; Parsons, P. G. Synthesis and spectroscopic characterisation of a combinatorial library based on the fungal natural product 3-chloro-4hydroxyphenylacetamide. Magn. Reson. Chem. 2007, 45, 442-445.

40. Khalifah, R. G. The Carbon Dioxide Hydration Activity of Carbonic Anhydrase. $J$. Biol. Chem. 1971, 246, 2561-2573.

41. Klengel, T.; Liang W.-J.; Chaloupka, J.; Ruoff, C.; Schroppel, K.; Naglik, J. R.; Eckert, S. E.; Mogensen, E. G.; Haynes, K.; Tuite, M. F.; Levin, L. R.; Buck, J.; 
Muhlschlegel, F. A. Fungal adenylyl cyclase integrates $\mathrm{CO}_{2}$ sensing with cAMP signaling and virulence. Curr. Biol. 2005, 15, 2021-2026.

42. Mogensen, E. G.; Janbon, G.; Chaloupka, J.; Steegborn, C.; Fu, M. S.; Moyrand, F.; Klenge, T.; Pearson, D. S.; Geeves, M. A.; Buck, J.; Levin, L. R.; Muhlschlegel, F. A.. Cryptococcus neoformans senses $\mathrm{CO}_{2}$ through the carbonic anhydrase Can2 and the adenylyl cyclase Cac1. Eukaryotic Cell 2006, 5, 103-111.

43. Poulsen, S.-A.; Davis, R. A.; Keys, T. G. Screening a natural product-based combinatorial library using FTICR mass spectrometry. Bioorg. Med. Chem. 2006, 14, 510515.

44. Innocenti, A.; Vullo, D.; Scozzafava, A.; Supuran, C. T. Carbonic anhydrase inhibitors: Interactions of phenols with the 12 catalytically active mammalian isoforms (CA IXIV). Bioorg. Med. Chem. Lett. 2008, 18, 1583-1587.

45. Innocenti, A.; Hilvo, M.; Scozzafava, A.; Parkkila, S.; Supuran, C. T. Carbonic anhydrase inhibitors: Inhibition of the new membrane-associated isoform XV with phenols. Bioorg. Med. Chem. Lett. 2008, 18, 3593-3596.

46. Innocenti, A.; Vullo, D.; Scozzafava, A.; Supuran, C. T. Carbonic anhydrase inhibitors: Inhibition of mammalian isoforms I-XIV with a series of substituted phenols including paracetamol and salicylic acid. Bioorg. Med. Chem. 2008, 16, 7424-7428.

47. Sentürk, M.; Gülçin, I.; Dastan, A.; Küfrevioglu, Ö., I.; Supuran, C. T. Carbonic anhydrase inhibitors. Inhibition of human erythrocyte isozymes I and II with a series of antioxidant phenols. Bioorg. Med. Chem. 2009, 17, 3207-3211.

48. Maresca, A.; Temperini, C.; Pochet, L.; Masereel, B.; Scozzafava, A.; Supuran, C. T. Deciphering the Mechanism of Carbonic Anhydrase Inhibition with Coumarins and Thiocoumarins. J. Med. Chem. 2010, 53, 335-344.

49. Carta, F.; Temperini, C.; Innocenti, A.; Scozzafava, A.; Kaila, K.; Supuran, C. T. Polyamines Inhibit Carbonic Anhydrases by Anchoring to the Zinc-Coordinated Water Molecule. J. Med. Chem., 2010, 53, 5511-5522.

50. DeLano, W. The PyMOL Molecular Graphics System. http://www.pymol.org

51. Alterio, V.; Hilvo, M.; Di Fiore, A.; Supuran, C. T.; Pan, P.; Parkkila, S.; Scaloni, A.; Pastorek, J.; Pastorekova, S.; Pedone, C.; Scozzafava, A.; Monti, S. M.; De Simone, G. Crystal structure of the catalytic domain of the tumor-associated human carbonic anhydrase IX. Proc. Nat. Acad. Sci. U.S.A. 2009, 106, 16233-16238. 
52. Teng, Y. B.; Jiang, Y. L.; He, Y. X.; He, W. W.; Lian, F. M.; Chen, Y.; Zhou, C. Z. Structural insights into the substrate tunnel of Saccharomyces cerevisiae carbonic anhydrase Nce103. BMC Struct. Biol. 2009, 67.

53. Schlicker, C.; Hall, R. A.; Vullo, D.; Middelhaufe, S.; Gertz, M.; Supuran, C. T.; Mühlschlegel, F. A.; Steegborn, C. Structure and inhibition of the $\mathrm{CO}_{2}$-sensing carbonic anhydrase Can2 from the pathogenic fungus Cryptococcus neoformans. J. Mol. Biol. 2009, 385, 1207-1220.

54. Buratowski, S. Progression through the RNA polymerase II CTD cycle. Mol Cell. 2009, 36, 541-546.

55. Pierens, G. K.; Carroll, A. R.; Davis, R. A.; Palframan, M. E.; Quinn, R. J. Determination of analyte concentration using the residual solvent resonance in $1 \mathrm{H}$ NMR spectroscopy. J. Nat. Prod. 2008, 71, 810-813.

56. Davis, R. A.; Kotiw, M. Synthesis of the fungal natural product (-)-xylariamide A. Tetrahedron Letts. 2005, 46, 5199-5201.

57. Lopez, M.; Paul, B.; Hofmann, A.; Morizzi, J.; Wu, Q. K.; Charman, S. A.; Innocenti, A.; Vullo, D.; Supuran, C. T.; Poulsen, S.-A. S-Glycosyl Primary Sulfonamides - A New Structural Class for Selective Inhibition of Cancer-Associated Carbonic Anhydrases. J. Med. Chem. 2009, 52, 6421-6432.

58. Leslie, A. Recent changes to the MOSFLM package for processing film and image plate data. Joint CCP4 + ESF-EAMCB Newsletter on Protein Crystallography 1992, 26.

59. Collaborative Computational Project Number 4. The CCP4 suite: programs for protein crystallography. Acta Crystallogr. D 1994, 50, 760-763.

60. Brünger, A.; Adams, P.; Clore, G.; Delano, W.; Gros, P.; Grosse-Kunstleve, R.; Jiang, J.; Kuszewski, J.; Nilges, N.; Pannu, N.; Read, R.; Rice, L.; Simonson, T.; Warren, G. Crystallography and NMR system (CNS): A new software system for macromolecular structure determination. Acta Crystallogr. D 1998, 54, 905-921.

61. Adams, P. D.; Afonine, P. V.; Bunkóczi, G.; Chen, V. B.; Davis, I. W.; Echols, N.; Headd, J. J.; Hung, L.; Kapral, G. J.; Grosse-Kunstleve, R. W.; McCoy, A. J.; Moriarty, N. W.; Oeffner, R.; Read, R. J.; Richardson, D. C.; Richardson, J. S.; Terwilliger, T. C.; Zwart, P. H. PHENIX: a comprehensive Python-based system for macromolecular structure solution. Acta Crystallogr. D 2010, 66, 213-221.

62. Schuettelkopf, A. W.; van Aalten, D. M. F. PRODRG - a tool for high-throughput crystallography of protein-ligand complexes. Acta Crystallogr. D 2004, 60, 1355-1363. 
63. Jones, T. A.; Zou, J. Y.; Cowan, S.; Kjeldgaard, M. Improved methods for building protein models in electron density maps and location of errors in these models. Acta Crystallogr. A 1991, 47, 110-119.

\section{Table of Contents Graphic}

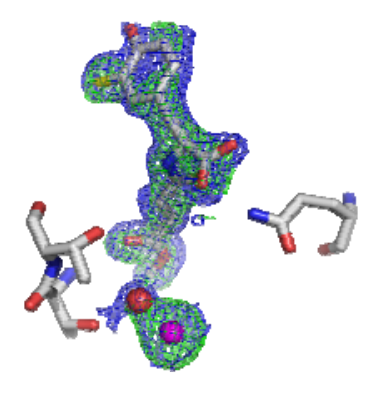

\section{CA inhibition profile}

Mycobacterial: $\mathrm{K}_{\mathrm{i}} \mathrm{s}=0.71-10.9 \mu \mathrm{M}$

Fungal: $\mathrm{K}_{\mathrm{i}} \mathrm{S}=1.06-1.11 \mu \mathrm{M}$

Human: $\mathrm{K}_{\mathrm{i}} \mathrm{S}=8.0-231 \mu \mathrm{M}$<smiles>COC(=O)/C=C/C(=O)NC(Cc1ccc(O)c(Cl)c1)C(=O)O</smiles> 